\title{
Faulting mechanism of the Campania-Lucania 1980 earthquake, Italy, from high-resolution, 3D velocity structure, aftershock relocation, fault-plane solutions, and post-seismic deformation modeling
}

\author{
Antonella Amoruso ${ }^{1}$, Luca Crescentini ${ }^{1}$, Bellina Di Lieto ${ }^{1}$, Roberto Scarpa ${ }^{2,{ }^{\star}}$ \\ ${ }^{1}$ Università di Salerno, Dipartimento di Fisica "E.R. Caianiello", Fisciano (Salerno), Italy \\ ${ }^{2}$ Università di Salerno, Dipartimento di Matematica e Informatica, Fisciano (Salerno), Italy
}

\author{
Article history \\ Received April 27, 2011; accepted August 24, 2011. \\ Subject classification: \\ Earthquake faults: properties and evolution, Earthquake source and dynamics.
}

\begin{abstract}
This study performs a detailed reconstruction of the rupture mechanism of the 1980 Campania-Lucania (southern Italy) earthquake. This is achieved by relocation of the main event through computation of faultplane solutions of the aftershocks, $P$-wave velocity inversion, and analysis of post-seismic ground deformation, which provide an overall picture of the faulting mechanism. All of these data are in favor of a complex rupture mechanism, as already identified by many studies, which consists of three separate events. The present study defines a graben-like rupture, with the first event rupturing a (>20-km-long) segment of a large, highangle, NE-dipping, SE-NW-striking, normal fault. The two successive ruptures occurred separately, the first along the southern segment, and the second along the northern segment, of a complementary SW-dipping, normal fault. This mechanism is well evidenced by the revised location of the hypocenter of the main event, and the location of the aftershocks and their fault-plane solutions, as well as by the underlying three-dimensional $P$-wave velocity structure. The model proposed by Amoruso et al. [2005a] that was based on the inversion of co-seismic vertical displacement data is confirmed by the present analyses, as it satisfies all of the available experimental observations, and better constrains the location and faultplane solutions of the aftershocks, the velocity discontinuities, and the rupture observations at the surface. This conclusion is also supported by analyses of the post-seismic data.
\end{abstract}

\section{Introduction}

After more than 30 years from its occurrence, the 1980 Campania-Lucania earthquake (Ms 6.9) remains one of the best documented Italian earthquakes. Many studies have analyzed the seismological, geodetic and surface fracture data, and in spite of some difference in the details, overall, all of these have shown a relatively consistent picture of the faulting geometry, as shown in Figure 1 [Crosson et al. 1986, Bernard and Zollo 1989, Pantosti and Valensise 1990, Pingue et al. 1993, Dalla Via et al. 2003, Amoruso et al. 2005a]. All of the models of the 1980 Campania-Lucania earthquake are in agreement with the indication of a complex rupture mechanism that consisted of three main fault segments that were activated in a time interval of about $1 \mathrm{~min}$ (hereinafter referred to as: the F1 event, as the first event; the F2 event, at $20 \mathrm{~s}$; and the F3 event, at $40 \mathrm{~s}$ ). The aftershocks occurred mostly inside of, or near to, the edges of the areas of maximum co-seismic slip.

The location of the F1 event was debated in Giardini et al. [1996], Westaway [1992], and Westaway and Jackson [1987], where the locations were obtained using a dense configuration of distant stations $(>100 \mathrm{~km})$ with good azimuthal coverage. However, distant stations cannot provide a reliable estimate of the depth. Moreover, the strong lateral velocity variations in Italy and in the central Mediterranean areas suggests that these locations can suffer systematic errors due to the incorrect inclusion of three-dimensional (3D) velocity models. In Del Pezzo et al. [1983], the location of the F1 event was performed using a set of 11 stations that were located in the $22-\mathrm{km}$ to $175-\mathrm{km}$ epicentral distance range, which included data from a temporary station managed by ENEA (GL9). A velocity model was derived using the simultaneous inversion procedure developed by Crosson [1976]. The location of the main shock is very close to the location indicated by Giardini et al. [1996], which thus appears as one of the most reliable.

Deschamps and King [1984] derived a set of 160 faultplane solutions using a minimum number of six first-arrival polarities, and they first showed the complexity of the stress distribution in the volume spanned by the aftershocks. For the source complexity, Westaway and Jackson [1987] proposed a model that consists of six sub-faults, on the basis of their waveform analysis of seismograms recorded at teleseismic distances. The early sub-events (1-4) share the same Apennine direction and are high-angle normal faults, while the later 
sub-events (5-6) are low-angle normal faults, which were interpreted as late dislocations of a large listric fault.

Bernard and Zollo [1989] mainly analyzed strongmotion records, and they suggested the occurrence of a bilateral first rupture that evolved (about $20 \mathrm{~s}$ later) into a low-angle normal fault (the F2 event) in the southern segment, and then (about $40 \mathrm{~s}$ later) into another high-angle fault (the F3 event), antithetic to the first and striking along the same direction.

Cocco and Pacor [1993] inverted low-pass filtered $(<2.5-$ $\mathrm{Hz}$ ) strong-motion accelerograms and obtained a model with a heterogeneous bilateral rupture that did not propagate uniformly away from the hypocenter. They suggested that the rupture propagated northwestwards, along a further fault fragment for which no surface evidence was observed.

In spite of some general agreement between these models, the inversion of the waveforms of strong-motion records suffers a lack of absolute timing, and thus a relatively large instability in the extraction of the source parameters is expected. Local effects, as revealed in at least two of the accelerometric stations (namely, Sturno and Calitri), together with the inversion procedures used for the derivation of the velocity models, also affect the study of aftershocks and the interpretation of source modeling. Three-dimensional velocity inversion, which was aimed at also obtaining the aftershock hypocenters, was performed by Amato and Selvaggi [1993] on a dataset that included 621 aftershocks that were recorded by at least eight stations, and this provided the first evidence of strong P-wave velocity variations along the 1980 rupture segments.

Moreover, Pantosti and Valensise [1990] analyzed the pattern of surface faulting traces and compared the results with the vertical displacement observations, and they concluded that the dip of the fault responsible for the F2 event was a high-angle one. In contrast, after inverting vertical displacement data, Pingue et al. [1993] proposed a three-fault model that is similar to the Bernard and Zollo [1989] model, with the main difference being the dip of the F2 event, which is as a low angle up to the surface. However, there are large discrepancies between the measurements and predictions along the leveling lines (e.g. see Figure 2 in Pingue et al. [1993]).

Most of these models were critically reviewed in a special issue of Annals of Geophysics (then Annali di Geofisica; 36, $1,1993)$, and in some cases they were slightly changed with respect to those originally proposed.

More recently, inversions of the available leveling data have shed more light on the fault geometry, slip distribution, and post-seismic deformation. Dalla Via et al. [2003] used the data of the two leveling surveys that were carried out in 1981 and 1985 to study the post-seismic deformation. They considered that the main faults were divided into sub-faults, and they inferred a local Earth model. Dalla Via et al. [2005] analyzed co-seismic vertical displacement data to determine the slip distribution over the fault planes, and in a second stage, they analyzed post-seismic leveling data to reveal viscoelastic relaxation. Amoruso et al. [2005a] analyzed the co-seismic deformations and concluded that the F2 event could be ascribed to either a northeast-dipping, subhorizontal fault, or a southwest steeply dipping fault, with these two solutions being statistically indistinguishable. The latter possibility suggests that the F2 event can be interpreted as a repetition of the southern rupture of the 1694 earthquake, and it is more consistent with the aftershock distribution in the southern part of the epicentral area.

In the present study, we have analyzed seismic and deformation data with the aim of improving the knowledge of the source mechanism of the 1980 Campania-Lucania earthquake. We have relocated the F1 event and F3 event ruptures, determined the preliminary spatial distributions of the aftershocks using HYPO71PC [Lee and Valdes 1985], and computed the focal mechanisms of up to 247 aftershocks using FPFIT [Reasenberg and Oppenheimer 1985]. We thus provide here the most complete set of solutions that have been derived to date from the data related to the 1980 Campania-Lucania earthquake. We have also recalculated the spatial distribution of the aftershocks, and jointly, the 3D velocity model, using the FDTOMO software [Benz et al. 1996]. We have performed inversions, after highlighting of the role of the smoothing parameter k. Finally, we have analyzed the data related to the post-seismic deformation using VISCO1D, version 3 [Pollitz 1992], with the aim of distinguishing between different uniform-slipping faults [Dalla Via et al. 2003, Amoruso et al. 2005a] and Earth models [modified from Amoruso et al. 2005b, Dalla Via et al. 2003, Dalla Via et al. 2005, and Bagh et al. 2007].

\section{Datasets}

The distribution of the aftershocks was investigated here using data from a temporary seismic network that was deployed soon after the main event. The seismic stations used reached a maximum number of 32 , and they were operating mainly in the period from 1-15 December, 1980. P-wave readings have errors of about $0.1 \mathrm{~s}$ to $0.2 \mathrm{~s}$, which depend on the quality of the records, as the seismographs were mostly from smoked drums or thermal sensitive paper, with only a few from magnetic tape records. During the main event, only one local station was operating (GL9, located at Guardia dei Lombardi; Figure 1a, blue triangle), but the number rapidly increased in the following days. Strong-motion records were also available in the near field at 12 stations, with clear shearwave arrivals, although these data suffer from a lack of absolute timing. We have to note that some errors in the published station locations led to misleading interpretations based on these data only, e.g. as in the case of the Bovino accelerometer (Figure 1a, blue diamond). Details of the data used for the location of the F1 and F3 events are given in Table 1. 

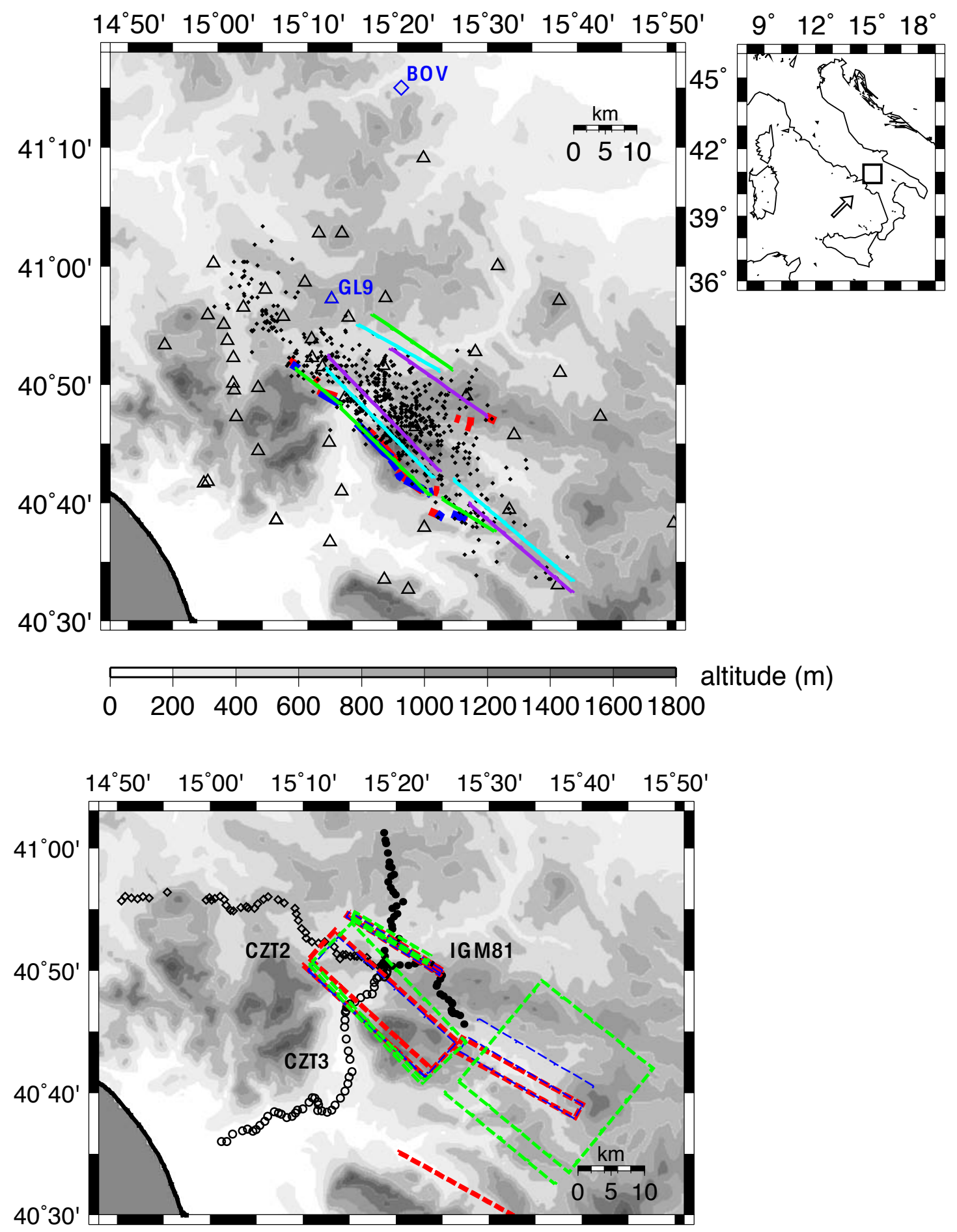

Figure 1. Maps of the study area showing the main fault systems of the 1980 earthquake: (a) Traces of the fault planes: green, Pantosti and Valensise [1990]; cyan, Pingue et al. [1993]; purple, Bernard and Zollo [1989]. Blue thick solid lines, fault scarps identified by Pantosti and Valensise [1990]; red thick solid lines, fault scarps identified by Blumetti et al. [2002]. Triangles, locations of the seismic stations; blue triangle, GL9 station; blue diamond, location of the Bovino accelerometer; black diamonds; epicenters of the earthquakes that occurred in the period of December 1 to 15, 1980. Inset: Location of study area within Italy. (b) Surface projection of the fault planes: green, Dalla Via et al. [2003]; red, Amoruso et al. [2005a], type A; blue, Amoruso et al. [2005a], type B. Black diamonds, location of benchmarks of the CZT2 leveling line; black circles, location of benchmarks of the CZT3 leveling line; black points, location of benchmarks of the IGM81 leveling line used in the present study.

We selected 629 aftershocks from the whole seismic dataset for tomographic inversion and earthquake relocation, considering the number of stations that recorded the event (that must be $>5$ ) and the quality of the preliminary locations (standard errors on locations $<5 \mathrm{~km}$, and RMS $<0.5 \mathrm{~s}$ ). For the derivation of the fault-plane solutions, we considered the seismic data with a minimum number of 10 or 15 polarity readings.

The data used for the post-seismic modeling were collected along three high-precision leveling lines (Figure 1b, 


\begin{tabular}{ccc}
\hline Location & Authors & Method, data \\
\hline $40.803 \mathrm{~N}, 15.302 \mathrm{E}$ & Giardini et al. [1996] & Multiple master location, Pn \\
$40.724 \mathrm{~N}, 15.414 \mathrm{E}, \mathrm{H}=10-12 \mathrm{~km}$ & Westaway [1992] & Relative, Pn \\
$40.778 \mathrm{~N}, 15.332 \mathrm{E}, \mathrm{H}=12 \mathrm{~km}$ fixed & Westaway and Jackson [1987] & Relative, Pn \\
$40.767 \mathrm{~N}, 15.304 \mathrm{E}, \mathrm{H}=16 \mathrm{~km}$ & Del Pezzo et al. [1983] & Absolute, Pg-Pn at 11 stations \\
\hline
\end{tabular}

Solutions obtained in the present study using HYPO71PC *

\begin{tabular}{|c|c|c|}
\hline Nucleation point & Horizontal distance $(\mathrm{km})$ & Hypocenter of F3 event \\
\hline $\begin{array}{c}\text { First location: } \\
40.765 \mathrm{~N}, 15.302 \mathrm{E}, \mathrm{H}=19.4 \mathrm{~km} ; \\
11 \text { regional stations } \\
\text { in the distance range } 22-175 \mathrm{~km} \text {; } \\
\text { RMS .14 GAP 122 ERH } 1.3 \mathrm{ERZ} 0.8\end{array}$ & $\begin{array}{l}\text { First to second location: } \\
1.3\end{array}$ & $\begin{array}{c}40.794 \mathrm{~N}, 15.414, \mathrm{H}=6 \text { fixed; } \\
5 \mathrm{~S}-\mathrm{P}\end{array}$ \\
\hline
\end{tabular}

Second location:

$40.755 \mathrm{~N}, 15.297 \mathrm{E}, \mathrm{H}=18.7 \mathrm{~km}$;

22 regional stations

in the distance range $20-175 \mathrm{~km}$,

including S-P from 12 accelerograms;

RMS .22 GAP 122 ERH 0.5 ERZ 0.5

Third location:

40.759N, 15.300E, $\mathrm{H}=17.9 \mathrm{~km}$;

11 accelerometric stations

in the distance range $20-175 \mathrm{~km}$, including

only S-P arrivals at accelerometric stations;

RMS 0.12 GAP 122 ERH 0.3 ERZ 0.3
First to third location:

0.7

* No inverted $1 D$ velocity models and station residuals added.

Table 1. Hypocenter locations of the Campania-Lucania 1980 earthquake.

CZT2, CZT3, IGM81) that were run in the spring of 1981 and in 1985, and which consist of elevation differences between the two campaigns measured on 159 benchmarks of the leveling lines; namely, 55 benchmarks of line IGM81, 47 benchmarks of line CZT2, and 57 benchmarks of line CZT3. The field measurements were performed according to the criteria of high-precision leveling (i.e. $t= \pm 0.25 \sqrt{L} \mathrm{~cm}$, where $t$ is the tolerance of the difference between the fore and back leveling between two subsequent benchmarks, and $L$ is the distance between the two benchmarks in kilometers). The three profiles mainly cover the western part of the epicentral area and the main fault surface projection, with poor information provided related to the post-seismic deformation recovered from the eastern and southern parts of the epicentral area.

\section{Mainshock - aftershock distribution and velocity model}

Location of the first rupture

We recomputed the location (Table 1) of the first rupture, the F1 event, using HYPO71PC [Lee and Valdes 1985 ] and the S-P arrivals read at 12 accelerometric stations.
The results are similar (with the reliability of the solution increased) and show overlap within the reading errors (the total RMS is in the $0.1 \mathrm{~s}$ to $0.2 \mathrm{~s}$ range, leading to standard errors for the locations that are $<1 \mathrm{~km}$ ). We also relocated the $\mathrm{F} 3$ event (Table 1), confining the location to about $10 \mathrm{~km}$ north of the $\mathrm{F} 1$ event.

\section{D hypocenter parameters}

The 1D velocity model was obtained from inversion of the travel-times using the VELEST algorithm [Kissling et al. 1994], and it is reported in Table 2. Significant station corrections, of up to $1 \mathrm{~s}$, were found for stations located in the eastern sectors, which indicated the presence of pronounced lateral velocity inhomogeneities. The velocity model was used as the starting model for the retrieval of the source parameters of all of the events in the period of December 1 to 15, 1980 (see Figure 2, where the events that occurred from 1982 to 2008 are also shown). The same velocity model was also used as the starting model for the retrieval of the source parameters of all of the events in the periods of November 23 to 30 and December 16 to 31, 1980 (Figure 2, purple diamonds). 
P velocity model

\begin{tabular}{cc}
\hline Depth $(\mathbf{k m})$ & $\mathbf{V}_{\mathbf{p}}(\mathbf{k m} / \mathbf{s})$ \\
\hline 0 & 4.5 \\
3 & 5.3 \\
7 & 6.0 \\
10 & 6.2 \\
15 & 6.3 \\
\hline
\end{tabular}

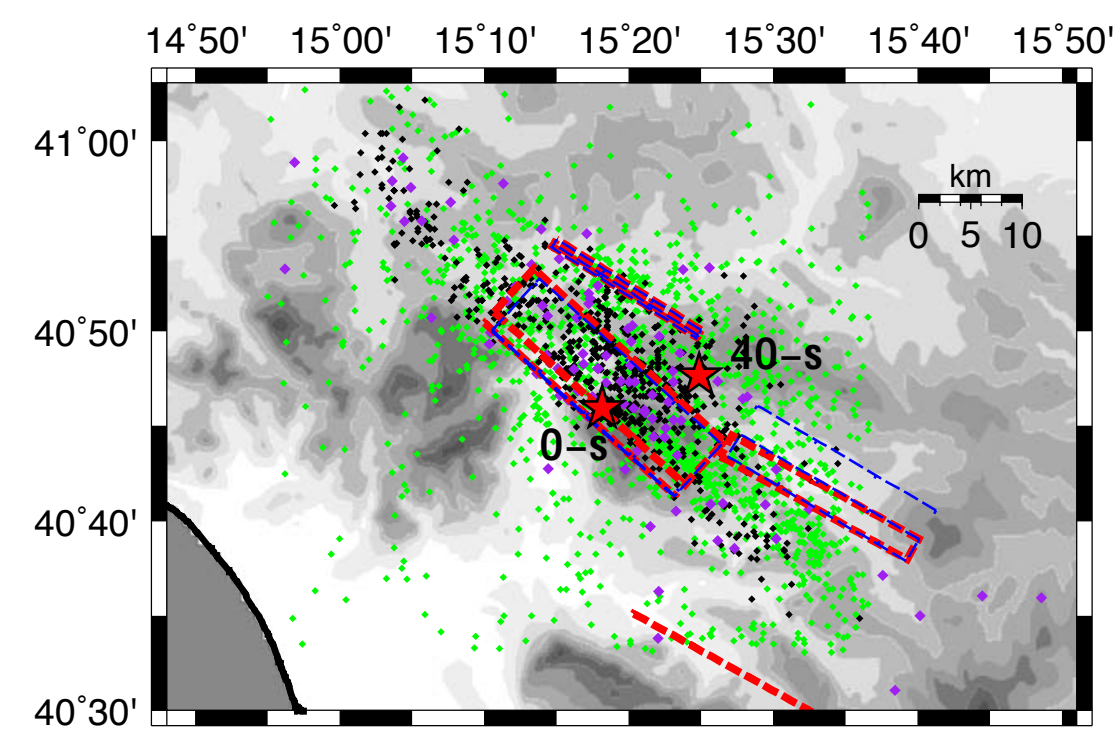

Table 2 (left). The 1D velocity model. Figure 2 (right). Map of the study area showing the spatial distribution of the earthquakes that occurred after the November 23, 1980 event. Black diamonds, epicenters of the earthquakes that occurred in the period of December 1 to 15, 1980. Purple diamonds, epicenters of the earthquakes that occurred in the period of November 23 to 30 and December 16 to 31, 1980. Green diamonds, epicenters of the earthquakes that occurred in the period of 1982 to 2008 (from the INGV catalog: http:// csi.rm.ingv.it). Stars, locations of the main rupture, as reported in Table 1; red and blue rectangles and dashed segments, surface projections and traces of the fault planes of Amoruso et al. [2005a], types A and B, respectively.

\section{Fault-plane solutions}

Using the criteria from Deschamps and King [1984] we obtained more than 600 fault-plane solutions, although we preferred to be more conservative, and only took into account those events with more than 10 and 15 polarity readings, thus dealing with 247 and 80 fault-plane solutions, respectively. For the sake of clarity, we show the data relative to the 15 polarity readings only. The magnitude of the 80 selected events was above 1.5 (range, 2-4). We estimated the fault-plane solutions using FPFIT [Reasenberg and
Oppenheimer 1985], which gives double-couple fault-plane solutions from P-wave first-motion data using a grid-search method. The uncertainties of fault-plane solutions, which derive mostly from the inaccuracy in the velocity model, were estimated to be around $10^{\circ}$ for the $\mathrm{P}, \mathrm{T}$ and null axes.

We also attempted to recalculate the fault-plane solutions using a preliminary $3 \mathrm{D}$ velocity model (obtained as explained below).

Figures 3 and 4 show these 80 computed focal mechanisms.
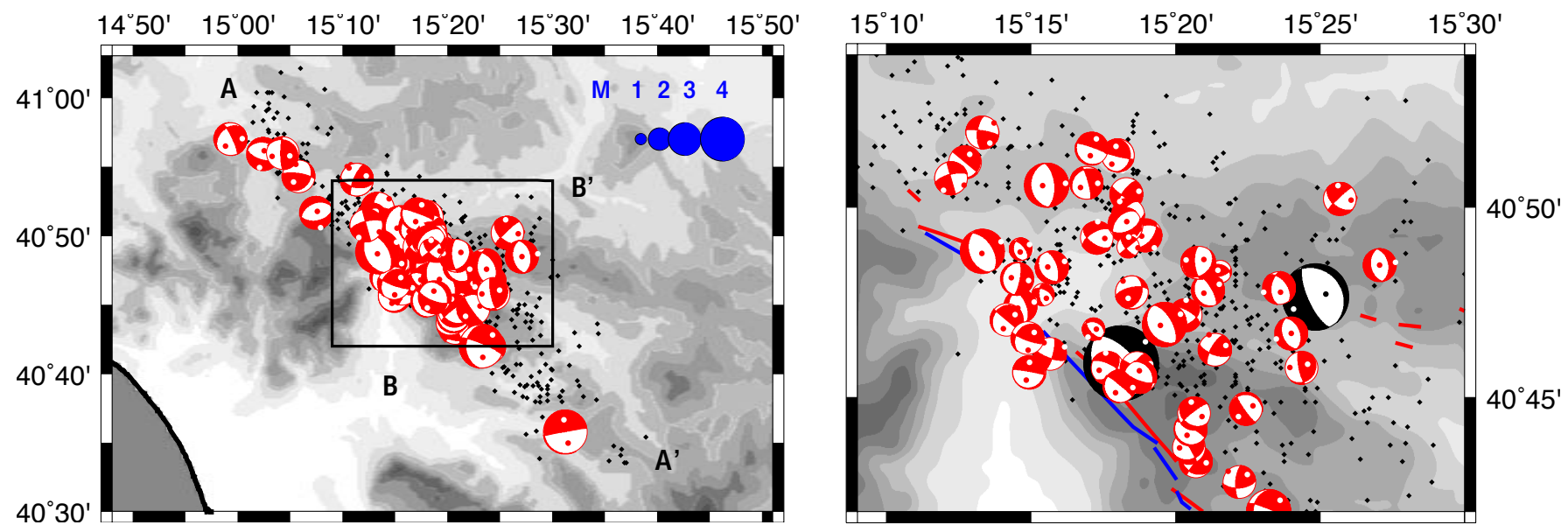

Figure 3. Maps of the study area. Left panel: Fault plane solutions obtained by selecting 80 aftershocks recorded at more than 15 stations. The sizes of the focal spheres are proportional to the magnitudes of the event (see blue balls scale). Rectangle, area shown in the right panel. AA' and BB', vertical sections reported in Figure 4a, b. Right panel: Fault plane solutions obtained by selecting aftershocks recorded at more than 15 stations (red beach balls) and the focal mechanisms of the F1 and F3 events (black beach balls) [Amoruso et al. 2005a]. Blue thick solid lines, fault scarps identified by Pantosti and Valensise [1990]; red thick solid lines, fault scarps identified by Blumetti et al. [2002]. 
AA' Profile - distance $(\mathrm{km})$

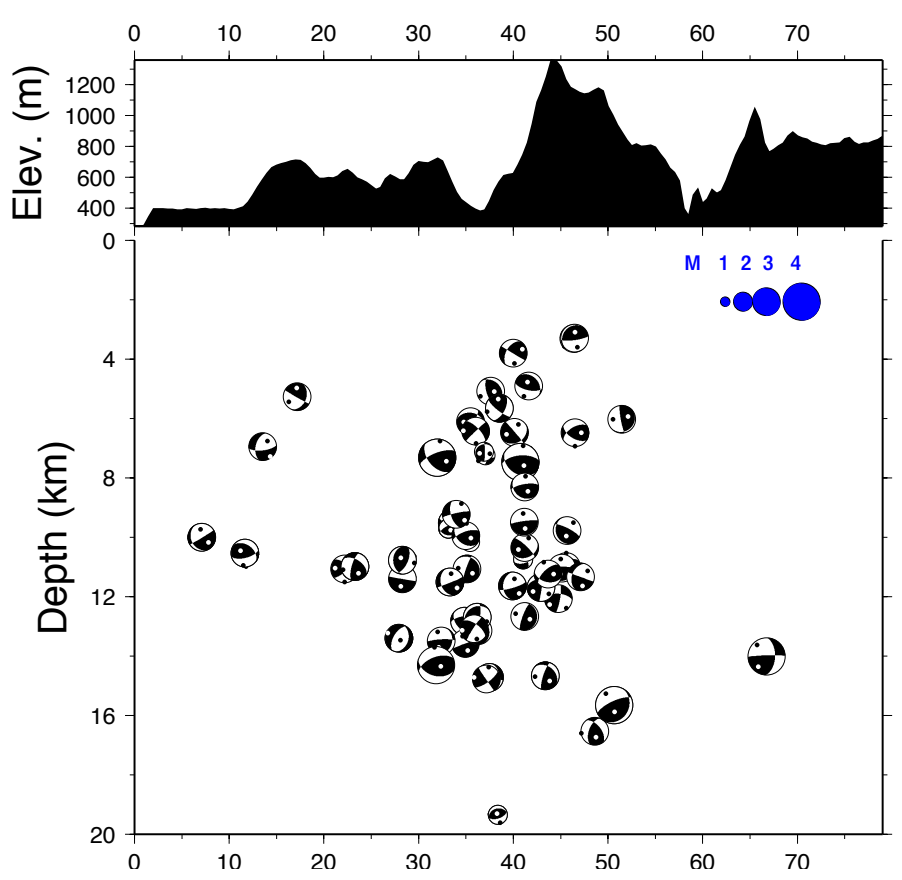

BB' Profile - distance (km)

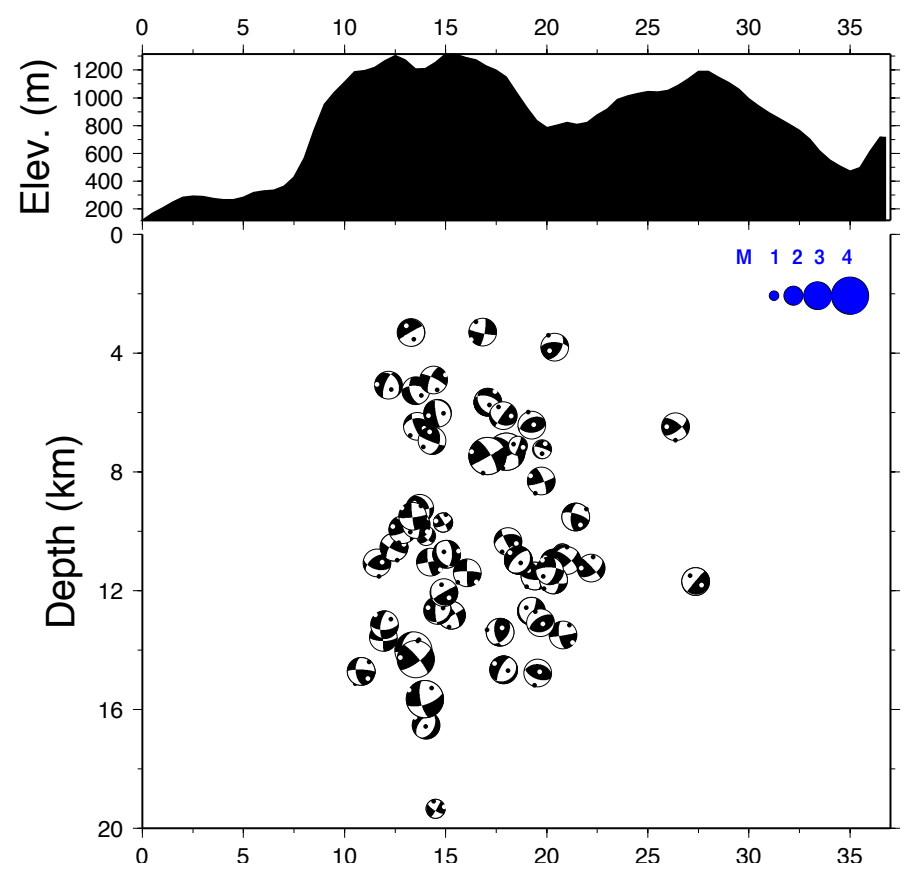

Figure 4. Vertical sections along the $\mathrm{AA}^{\prime}$ (a) and $\mathrm{BB}^{\prime}(\mathrm{b})$ profiles from Figure 3, showing the fault plane solutions obtained by selecting aftershocks recorded at more than 15 stations. The sizes of the focal spheres are proportional to the magnitudes of the event (see blue balls scale).

Next page: Figure 5 (top). Coverage of ray paths used for travel-time inversions. Left panel: map of the first layer (depth range $-1 \mathrm{~km}$ to $1 \mathrm{~km}$, because of the presence of topography, characterized by an average elevation of $1 \mathrm{~km}$ ). Right panels: vertical sections along BB' (upper plot) and EE' (lower plot) White triangles, locations of the seismic stations. Figure 6 (bottom). Checkerboard tests, comparing the true (left panels) and the reconstructed (right panels) velocity models in the second layer (upper panels) and two vertical sections, along AA' (middle panels) and BB' (lower panels).

\section{Sensitivity test for the velocity model}

To test the stability of the resulting velocity models, we first investigate the ray coverage (Figure 5), which represents the accumulated ray length per cell sampled by the $S$-wave dataset, using FDTOMO [Benz et al. 1996]. Values $>20$ typically mean that the cell is sampled by approximately 10 or more rays, given a cell dimension of $2 \mathrm{~km}$. The central part of the aftershock region, which covered a surface of $50 \mathrm{~km} \times 10 \mathrm{~km}$ in a depth range $3 \mathrm{~km}$ to $13 \mathrm{~km}$, was well sampled by the rays. The best resolution is thus obtained in this area, which surrounds the main fault segments.

We also performed checkerboard tests to highlight the resolution that can be achieved with our seismic network geometry. We computed the synthetic P-wave arrival times using the source-receiver geometry of the observed P-wave datasets and the checkerboard velocity model described by P-wave velocities that alternate between $4.5 \mathrm{~km} / \mathrm{s}$ to 5.5 $\mathrm{km} / \mathrm{s}$ (Figure $6,2 \mathrm{~km} \times 2 \mathrm{~km}$ box dimensions). In addition, the velocity model was smoothed so that the peak variations were two cells wide. The initial velocity model used in the synthetic reconstruction is homogeneous (P-wave velocity, $5.0 \mathrm{~km} / \mathrm{s}$ ). The results show that the network can reveal patches of high and low velocity areas with a spatial resolution of $2 \mathrm{~km}$, in the depth range of $0 \mathrm{~km}$ to $15 \mathrm{~km}$, and in the whole region covered by the dense ray paths. Note that the space grid used for these tests was smaller than that used in the inversion, to get conservative indications of the resolution.

\section{D tomographic inversion and earthquake relocation}

\section{Method}

The linearized iterative tomographic approach proposed by Benz et al. [1996] was used to compute the 3D velocity structure and the earthquake relocation. A brief description of the basics of the FDTOMO code follows, to highlight the role of the smoothing coefficient.

By parameterizing the reference velocity model as a uniform grid of constant slowness cells, which separate the slowness and hypocenter perturbations [Pavlis and Booker 1980, Spencer and Gubbins 1980], the set of equations that links the arrival time of a seismic wave (with reference to a starting velocity model and earthquake locations) to the slowness perturbations for each earthquake-receiver pair can be written in matrix form as:

$$
\gamma^{\prime}=B^{\prime} \Delta u
$$

where $\gamma^{\prime}$ is the arrival time residuals vector, $\boldsymbol{B}^{\prime}$ is the matrix that contains the length increases for each cell relative to the earthquake-station pair, and $\Delta \boldsymbol{u}$ is the vector containing the slowness perturbations. 

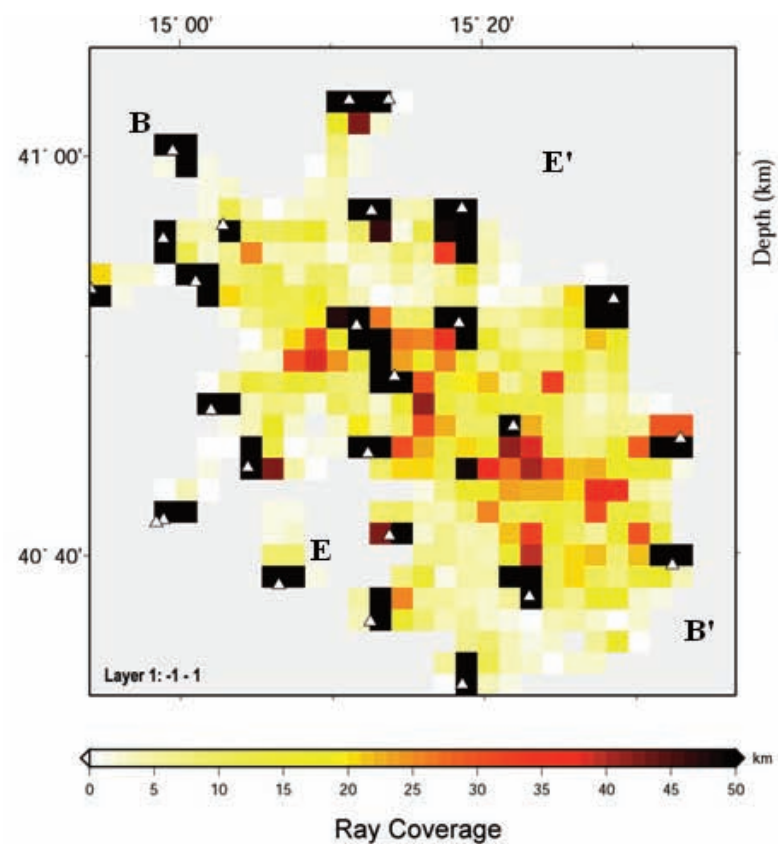

Figure 5 (caption on previous page)
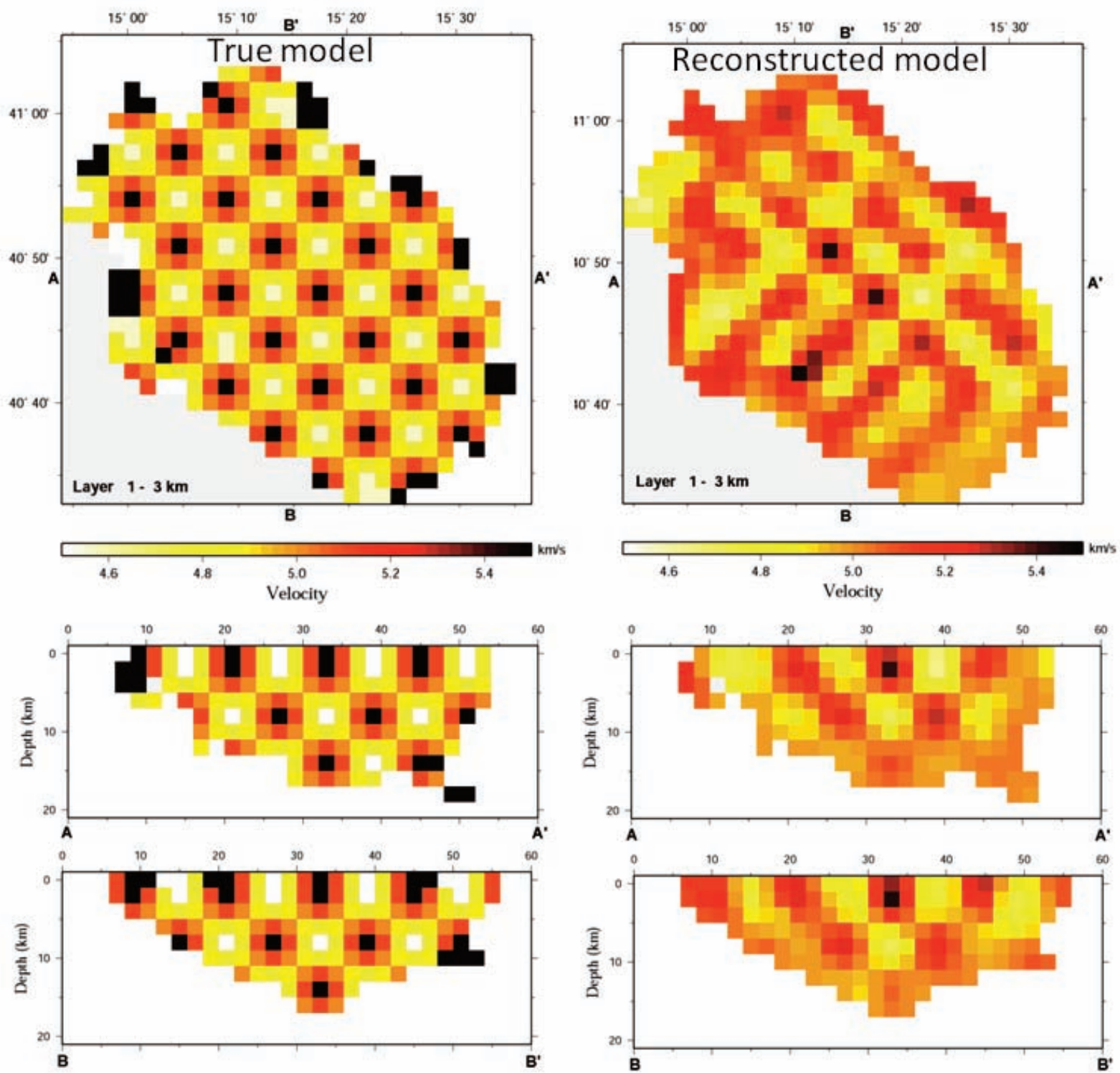

Figure 6 (caption on previous page). 
Equation (1) is solved using a least-squares QR algorithm, and to minimize artifacts due to model parameterization and solution instability, the Laplacian of the slowness field must vanish. Thus Equation (1) can be written in the form:

$$
\left[\begin{array}{c}
\boldsymbol{B}^{\prime} \\
k \boldsymbol{L}
\end{array}\right] \Delta \boldsymbol{u}=\left[\begin{array}{c}
\gamma^{\prime} \\
0
\end{array}\right]
$$

where $L$ is the set of smoothness-constraint equations, and the coefficient k governs the trade-off between the minimization of the data misfit and the model roughness. The coefficient $\mathrm{k}$ is tuned to minimize artifacts, as mentioned above.

\section{Results}

As a first step, the FDTOMO code was initially applied to retrieve the initial $3 \mathrm{D}$ velocity model used to obtain the fault-plane solution. As a second step, we reran the code and tried to quantify the robustness of the results by analyzing the effects of the dataset and computation input parameters.

We used two datasets of events in the magnitude ranges of 1.5 to 4.0 and 2.0 to 4.0 , which contained 629 and 213 earthquakes, respectively, to determine whether the results depended on the dataset. The former dataset contains the aftershocks that occurred in the period of December 1 to 15 , 1980 , and the dataset showed good quality of the preliminary locations (standard errors on locations $<5 \mathrm{~km}$; RMS $<0.5 \mathrm{~s}$ ). In the latter dataset, a more restrictive selection criterion for the number of stations $(>10)$ was used.The inversion procedure we follow for the final computations can be summarized as the following:

1) definition of a homogeneous starting half-space model;

2) hypocenter location of the 629 (213) aftershocks, using the homogeneous starting model;

3) computation of the velocity perturbations to the initial velocity model;

4) earthquake relocations using the updated velocity model.

Points 3 and 4 were iteratively repeated until the data misfit was reduced significantly, to achieve an asymptotic value.

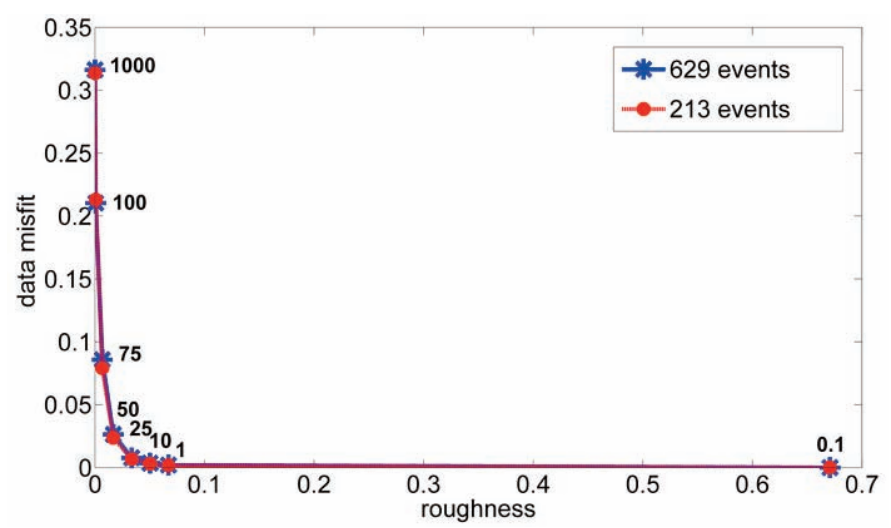

Figure 7. Trade-off curve for the selection of the damping parameter $\mathrm{k}$, obtained for the two different datasets of events. Each point or star on the curve represents one inversion carried out with the indicated value of $k$.
Tomographic reconstruction of $3 \mathrm{D}$ structures is sensitive to the quality of the data, the initial velocity model, the grid spacing, and particularly, the smoothing parameter $\mathrm{k}$. We performed several tests to obtain clues as to how the selection of input parameters, namely the smoothing factor $\mathrm{k}$ and the grid spacing, affected the relocation of the same event and the $3 \mathrm{D}$ velocity model. Our slight modifications of the code allowed the data misfit and model roughness to be obtained at each step of the inversion procedure, and drew the trade-off curves and estimated the best smoothing parameter $\mathrm{k}$. We tested various grids, through varying the cell sizes from $0.5 \mathrm{~km}$ to $10 \mathrm{~km}$ along each direction. The smoothing factor used remained constant inside each iteration, while varying every two iterations, following three different schedules: $[100,80,50,30,10],[10,8,5,3,1]$ and $[1$, $0.8,0.5,0.3,0.1]$. Finally, we compared the hypocentral coordinates obtained for two different grids, varying the smoothing parameter on ten iterations, for each range mentioned above, to quantify the discrepancies among the results. Our analysis showed that the P-velocity model is stable within the grid and the smoothing ranges considered, while the changes in these parameters affected the residuals and the earthquake relocations. The results (as the minimum associated residual) suggested that the best grid for our analysis has $5 \mathrm{~km} \times 5 \mathrm{~km} \times 3 \mathrm{~km}$ cells; a similar size can be estimated a priori from the source-receiver distance of our dataset, following the criteria reported in Benz et al. [1996].

We determined the best value of the smoothing parameter $\mathrm{k}$, running one iteration for different damping parameters on the better grid. Figure 7 shows the trade-off curves for the two datasets described above, and indicates the stability of the best $\mathrm{k}$ interval, which in both cases is of the order of 10 .

Figures 8 and 9 show the resulting velocity model and aftershock locations that were obtained on the grid with 5 $\mathrm{km} \times 5 \mathrm{~km} \times 3 \mathrm{~km}$ cells, by varying the value of the $\mathrm{k}$ parameter every two iterations, up to 10 iterations in the range $[10,8,5,3,1]$. Very similar data were obtained for the other schedules of the $\mathrm{k}$ parameter in the range suggested by the trade-off curves.

\section{Faulting geometery from leveling data: Methods and results}

The calculation of normal modes and post-seismic relaxation was carried out using the VISCO1D version 3 code [Pollitz 1992]. This was designed to describe the response of a spherically stratified elastic-viscoelastic medium to the stresses generated by an earthquake occurring in one of the elastic layers, in terms of spherical harmonic expansion of the spheroidal and toroidal motion components.

Thus the computations include:

1) Specification of a stratified Earth model (elastic moduli and viscosity of each layer); 

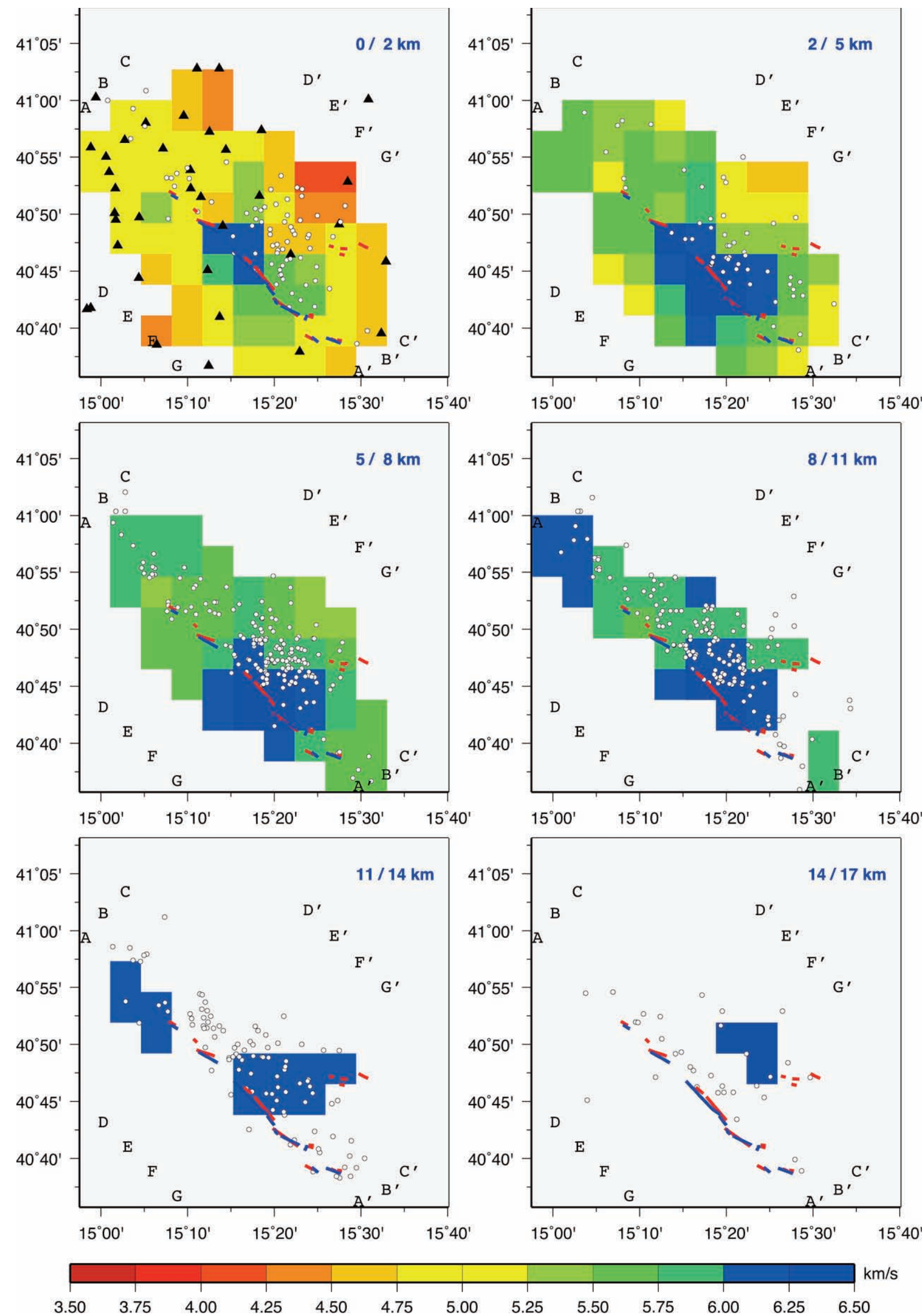

Figure 8. P-wave velocity models obtained from travel-time inversions for a 5-5-3 $\mathrm{km}$ grid, giving a layer thickness of $3 \mathrm{~km}$. Reported depth range in the upper-left plot is 0-2 km because of the presence of topography, characterized by an average elevation of $1 \mathrm{~km}$. Black triangles, seismic stations; open circles, aftershock hypocenters for each layer; blue thick solid lines, fault scarps identified by Pantosti and Valensise [1990]; red thick solid lines, fault scarps identified by Blumetti et al. [2002]. Letters from A to G and A' to G' indicate the start and end points of the profiles reported in Figure 9. 
AMORUSO ET AL.
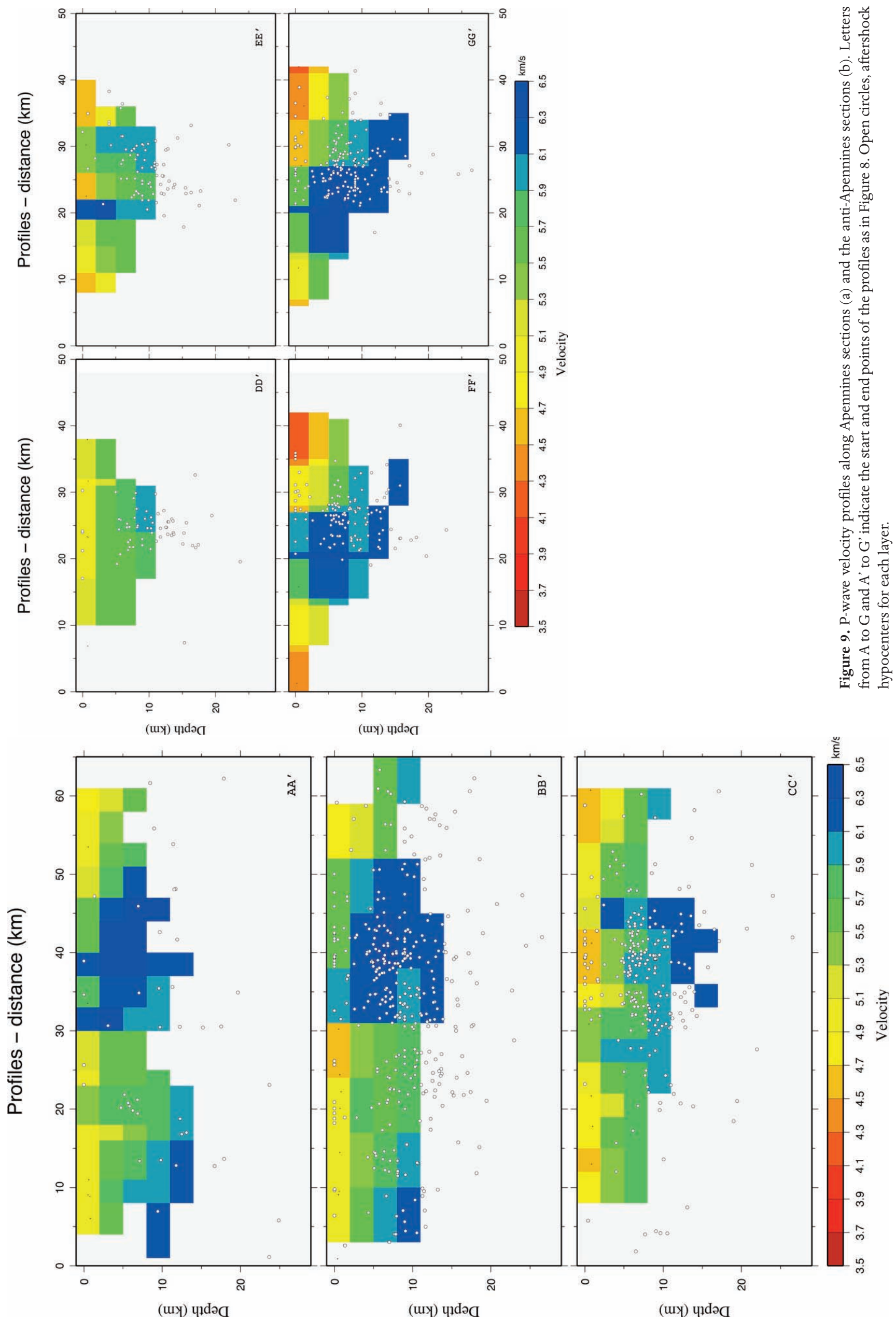
2) Identification of spheroidal and toroidal motion modes on this Earth;

3) Determination of the corresponding displacement-stress vectors for each of these modes;

4) Determination of the post-seismic deformation at specified times and observation points (latitude, longitude, depth), for a given source geometry and slip. It was possible to compute the non-gravitational viscoelastic response and an approximate gravitational viscoelastic response. We only show the results obtained from the non-gravitational viscoelastic response, as the gravitational viscoelastic response produces very similar results.

We used different Earth and fault models to identify, where possible, the models that best approximate the experimental data. In particular, we use Earth models modifed from Dalla Via et al. [2003, 2005], Amoruso et al. [2005b], and Bagh et al. [2007] (see Table 3, DVM, FM, BM, respectively). The fault models considered are those reported

\begin{tabular}{|c|c|c|c|c|c|}
\hline $\begin{array}{c}\mathbf{r}_{\text {inf }} \\
(\mathbf{k m})\end{array}$ & $\begin{array}{l}\mathbf{r}_{\text {sup }} \\
(\mathbf{k m})\end{array}$ & $\begin{array}{c}\rho \\
\left(10^{3} \mathrm{~kg} / \mathrm{m}^{3}\right)\end{array}$ & $\begin{array}{c}\mathrm{k} \\
\left(10^{10} \mathrm{~Pa}\right)\end{array}$ & $\begin{array}{c}\mu \\
\left(10^{10} \mathrm{~Pa}\right)\end{array}$ & $\begin{array}{c}\eta \\
\left(10^{18} \mathrm{~Pa} \cdot \mathrm{s}\right)\end{array}$ \\
\hline \multicolumn{6}{|l|}{ DVM } \\
\hline 5856.3 & 6291.0 & 3.390 & 12.25 & 7.350 & 100 \\
\hline 6291.0 & 6339.0 & 3.350 & 12.25 & 7.350 & 10 \\
\hline 6339.0 & 6343.0 & 2.900 & 5.92 & 3.550 & 10 \\
\hline 6343.0 & 6352.0 & 2.750 & 5.62 & 3.370 & 10 \\
\hline 6352.0 & 6371.0 & 2.650 & 5.42 & 3.250 & $10^{11}$ \\
\hline \multicolumn{6}{|l|}{ FM } \\
\hline 5284.4 & 5561.5 & 4.587 & 15.00 & 7.000 & 1000 \\
\hline 5561.5 & 5630.7 & 4.468 & 15.00 & 7.000 & 1000 \\
\hline 5630.7 & 5762.5 & 4.219 & 15.00 & 7.000 & 1000 \\
\hline 5762.5 & 5793.8 & 3.961 & 15.00 & 7.000 & 1000 \\
\hline 5793.8 & 5825.0 & 3.903 & 15.00 & 7.000 & 1000 \\
\hline 5825.0 & 5856.3 & 3.850 & 15.00 & 7.000 & 1000 \\
\hline 5856.3 & 5887.5 & 3.805 & 15.00 & 7.000 & 1000 \\
\hline 5887.5 & 5918.7 & 3.764 & 15.00 & 7.000 & 1000 \\
\hline 5918.7 & 5950.0 & 3.712 & 15.00 & 7.000 & 1000 \\
\hline 5950.0 & 5975.6 & 3.657 & 15.00 & 7.000 & 1000 \\
\hline 5975.6 & 6001.2 & 3.600 & 15.00 & 7.000 & 1000 \\
\hline 6001.2 & 6026.9 & 3.551 & 15.00 & 7.000 & 1000 \\
\hline 6026.9 & 6052.5 & 3.509 & 15.00 & 7.000 & 1000 \\
\hline 6052.5 & 6155.0 & 3.450 & 15.00 & 7.000 & 1000 \\
\hline 6155.0 & 6336.0 & 3.393 & 15.00 & 7.000 & 1000 \\
\hline 6336.0 & 6351.0 & 3.384 & 9.51 & 5.271 & 1 \\
\hline 6351.0 & 6359.0 & 3.190 & 7.36 & 4.080 & 10 \\
\hline 6359.0 & 6367.0 & 3.030 & 7.36 & 4.080 & $10^{11}$ \\
\hline 6367.0 & 6371.0 & 2.800 & 6.50 & 3.600 & $10^{11}$ \\
\hline \multicolumn{6}{|l|}{ BM } \\
\hline 5856.3 & 6291.0 & 3.390 & 12.250 & 7.350 & 100 \\
\hline 6291.0 & 6339.0 & 3.350 & 12.250 & 7.350 & 10 \\
\hline 6339.0 & 6343.0 & 2.900 & 5.920 & 3.550 & 10 \\
\hline 6343.0 & 6346.0 & 2.750 & 5.620 & 3.370 & 10 \\
\hline 6346.0 & 6355.0 & 2.910 & 8.163 & 4.268 & 10 \\
\hline 6355.0 & 6359.0 & 2.830 & 7.366 & 3.861 & $10^{11}$ \\
\hline 6359.0 & 6363.0 & 2.720 & 6.164 & 3.219 & $10^{11}$ \\
\hline 6363.0 & 6367.0 & 2.629 & 5.133 & 2.692 & $10^{11}$ \\
\hline 6367.0 & 6371.0 & 2.564 & 4.333 & 2.277 & $10^{11}$ \\
\hline
\end{tabular}

Table 3. Earth models: DVM, modifed from Dalla Via et al. [2003, 2005]; FM, modifed from Amoruso et al. [2005b]; BM, modified from Bagh et al. [2007]. $\mathrm{r}_{\text {inf }}$, bottom radius of each layer; $\mathrm{r}_{\text {sup, }}$, top radius of each layer; $\rho$, density; $\mathrm{k}$, bulk modulus; $\mu$, shear modulus, $\eta$, viscosity. 


\begin{tabular}{|c|c|c|c|c|c|c|}
\hline Event & $\begin{array}{c}\mathrm{L} 1 \\
(\mathrm{~km})\end{array}$ & $\begin{array}{c}\mathbf{L} 2 \\
(\mathbf{k m})\end{array}$ & $\begin{array}{l}\text { Top } \\
(\mathbf{k m})\end{array}$ & $\begin{array}{l}\text { Strike } \\
\left({ }^{\circ}\right)\end{array}$ & $\begin{array}{l}\text { Dip } \\
\left(^{\circ}\right)\end{array}$ & $\begin{array}{l}\text { Slip } \\
\text { (cm) }\end{array}$ \\
\hline \multicolumn{7}{|l|}{ DVF } \\
\hline $\mathrm{F} 1(0 \mathrm{~s})$ & 25 & 20 & 1.0 & 317 & 60 & 150 \\
\hline F2 (20 s) & 22 & 14 & 1.0 & 310 & 20 & 25 \\
\hline F3 (40 s) & 13 & 10 & 1.3 & 120 & 85 & 75 \\
\hline \multicolumn{7}{|l|}{ AAF } \\
\hline $\mathrm{F} 1(0 \mathrm{~s})$ & 25 & 11.3 & 2.5 & 312 & 60 & 255 \\
\hline $\mathrm{F} 2(20 \mathrm{~s})$ & 20.8 & 2.6 & 8.7 & 298.6 & 26.4 & 148 \\
\hline F3 (40 s) & 16.6 & 1.0 & 1.8 & 122.1 & 73.4 & 241 \\
\hline \multicolumn{7}{|l|}{ ABF } \\
\hline $\mathrm{F} 1(0 \mathrm{~s})$ & 24 & 13.6 & 0.2 & 312 & 60 & 267 \\
\hline F2 (20 s) & 20.2 & 6.2 & 7.5 & 120.2 & 66.5 & 71.9 \\
\hline F3 (40 s) & 16.6 & 1.2 & 1.7 & 122.0 & 72.0 & 201 \\
\hline
\end{tabular}

Table 4. Main parameters of the fault systems. DVF, Dalla Via et al. [2003]; AAF, Amoruso et al. [2005a], type A; ABF, Amoruso et al. [2005a], type B. L1, fault length; L2, fault width; Top, depth of fault top margin.

in Dalla Via et al. [2003] and in Amoruso et al. [2005a] (type $\mathrm{A}$ and $\mathrm{B}$; i.e. including a low-angle, northeast-dipping, and a steep southwest-dipping, F2 fault, respectively), considering a uniform distribution of slip on the faults (see Table 4, DVF, $\mathrm{AAF}$, and $\mathrm{ABF}$, respectively).

Figures 10, 11 and 12 show the predictions of the different Earth and fault models and the experimental data. Vertical displacements were plotted for each benchmark of the three leveling lines, IGM81, CZT2 and CZT3, respectively. For the sake of completeness, Figures 13 and 14 show the maps of the computed cumulative post-seismic vertical displacements for AAF and the DVM and BM Earth models, and for ABF and the DVM and BM Earth models, respectively.

\section{Discussion and conclusions}

The results shown in Table 1 indicate good reliability of the hypocentral parameters, with a significant improvement when compared with previously published data. The locations of the first rupture are much closer to each other compared with those from the literature (horizontal distance among pairs of epicenters, 1.3, 0.7 and $0.6 \mathrm{~km}$ against a minimum value of about $4 \mathrm{~km}$ for the data from the literature). The computed focal depths are very close to each other (within 1.5 $\mathrm{km}$ ), while the minimum depth difference for the focal depths from the literature is about $4 \mathrm{~km}$.

It can be seen that the locations of the first rupture (Table 1) approach the western border of the aftershock region, at a depth of about $18 \mathrm{~km}$. This thus contributes to validation of the source process, such as that discussed by Bernard and Zollo [1989] and Valensise et al. [1989], and it certainly excludes that proposed by Westaway [1992]. Moreover, the location of the F3 event is in agreement with the suggestions of Bernard and Zollo [1989], although the reliability is increased here, essentially because by checking in the field, we discovered a previous error in the coordinates of the Bovino accelerometer.
For the aftershock locations, the same stable configuration of the aftershocks within the area that ruptured during the 1980 event is envisaged also for more recent years (Figure 2). Normal faulting motion is evident from Figures 3 and 4 . A cluster of events located along a plane almost parallel to the main aftershock distribution can be envisaged: the cluster is characterized by an extension of approximately $20 \mathrm{~km}$, along the main fault segment of the F3 event. The geometry of this rupture is similar to the main phase, and the scattering of the stress axes in the northern part of the epicentral area appears to indicate a strong interaction between these two faults.

The main features of the inverted velocity models (Figures 8 and 9) indicate relatively low P-wave velocities in the region located NW from the fault traces, and relatively higher P-wave velocities in the southern region, which correspond to the limestone platform, and which is consistent with results previously obtained by Amato and Selvaggi [1993] and Pingue et al. [1988]. However, we used a larger number of earthquakes and we performed an accurate preliminary analysis of the effects of different computing conditions and of selection of the aftershock dataset. The retrieved velocity model is in good agreement with the $1 \mathrm{D}$ velocity inversion, which shows larger residuals for all of the stations located north of the faults, as compared to the southern stations, with an average residual of $1 \mathrm{~s}$.

For the post-seismic geodetic data, post-seismic relaxation induces a long-wavelength signal in the data, in contrast to the short-wavelength signals, which should be due, for example, to benchmark instability. The results of the different tests (Figures 10,11 and 12) suggest that the most appropriate Earth model is that referred to here as DVM (which is almost equivalent to the BM model). Such equivalence is not surprising, considering the similarities in DVM and BM, which differ only slightly (e.g. in the density and bulk modulus in the upper crust), and the differences with respect 

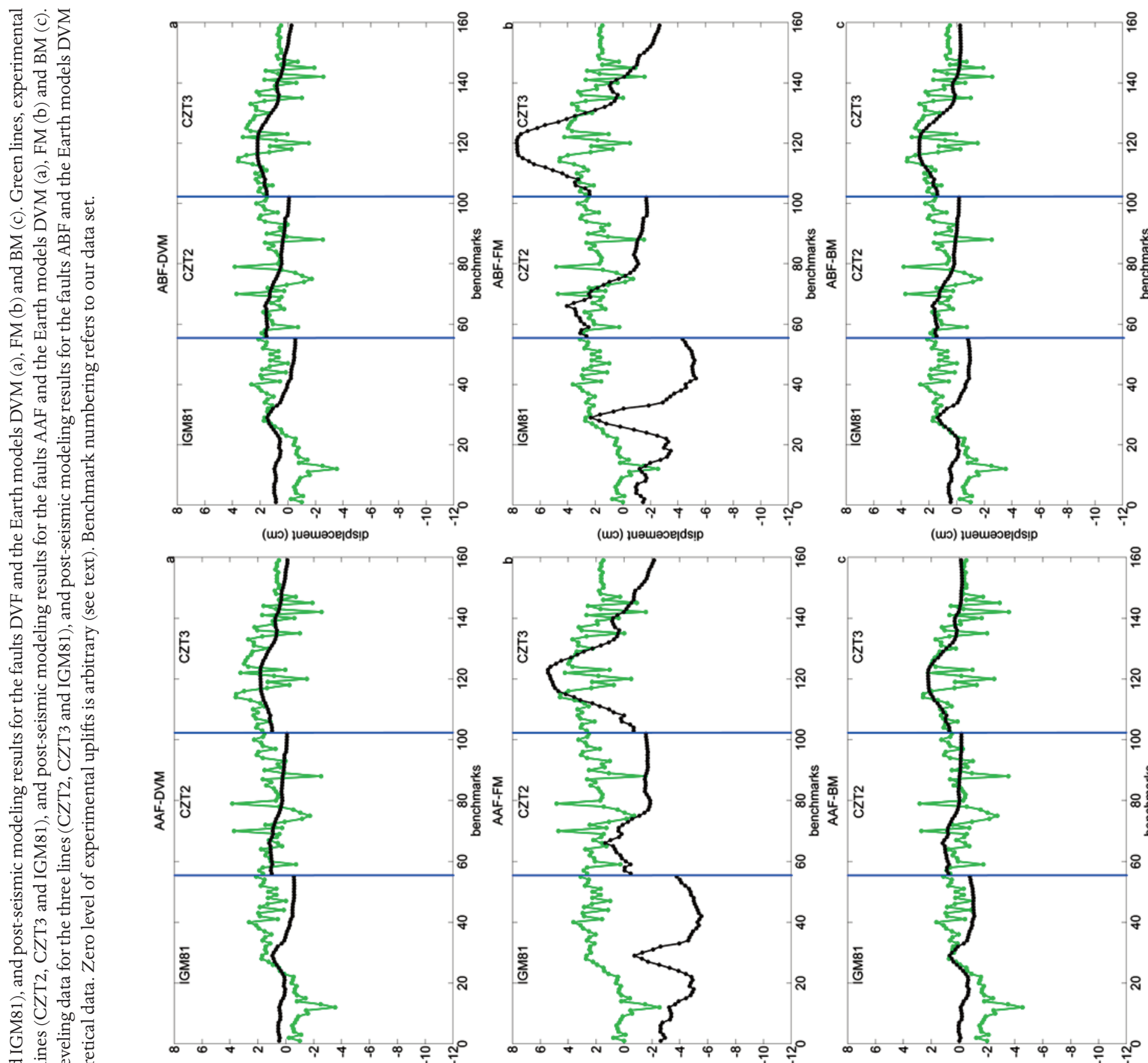

岂

N

군

记苞苞

䑰

沗范

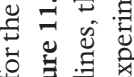

额苛

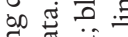

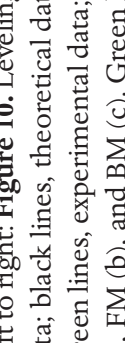
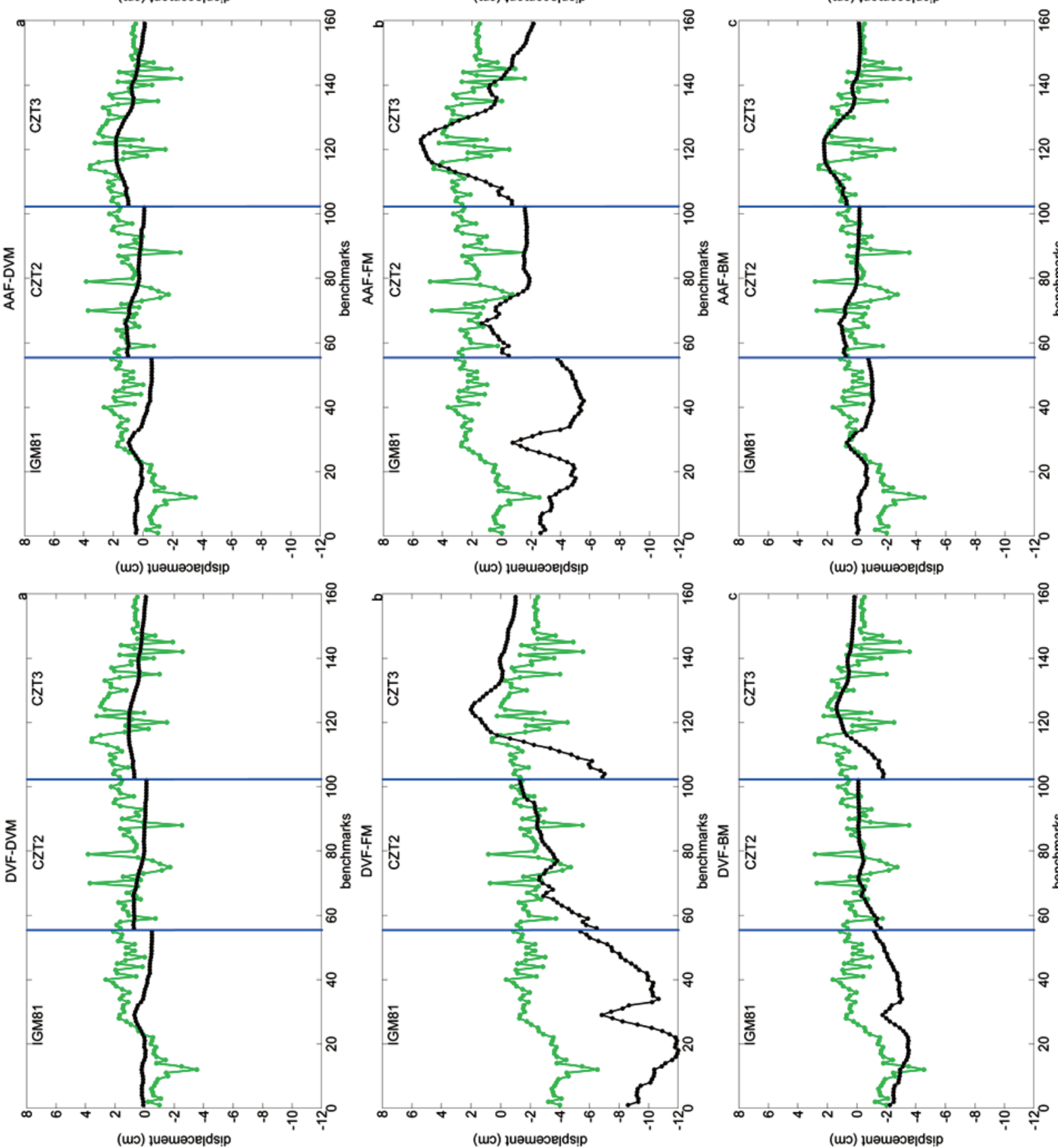

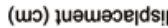

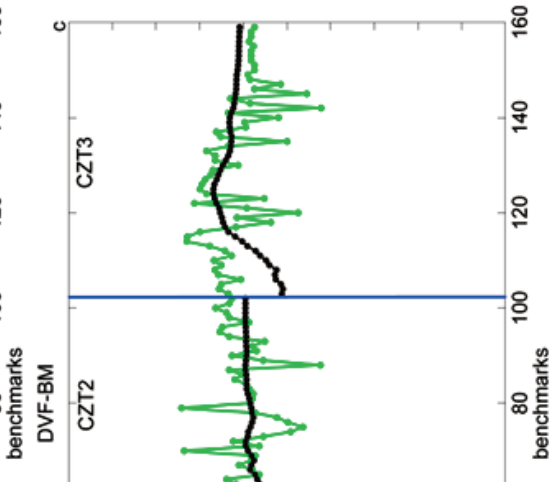



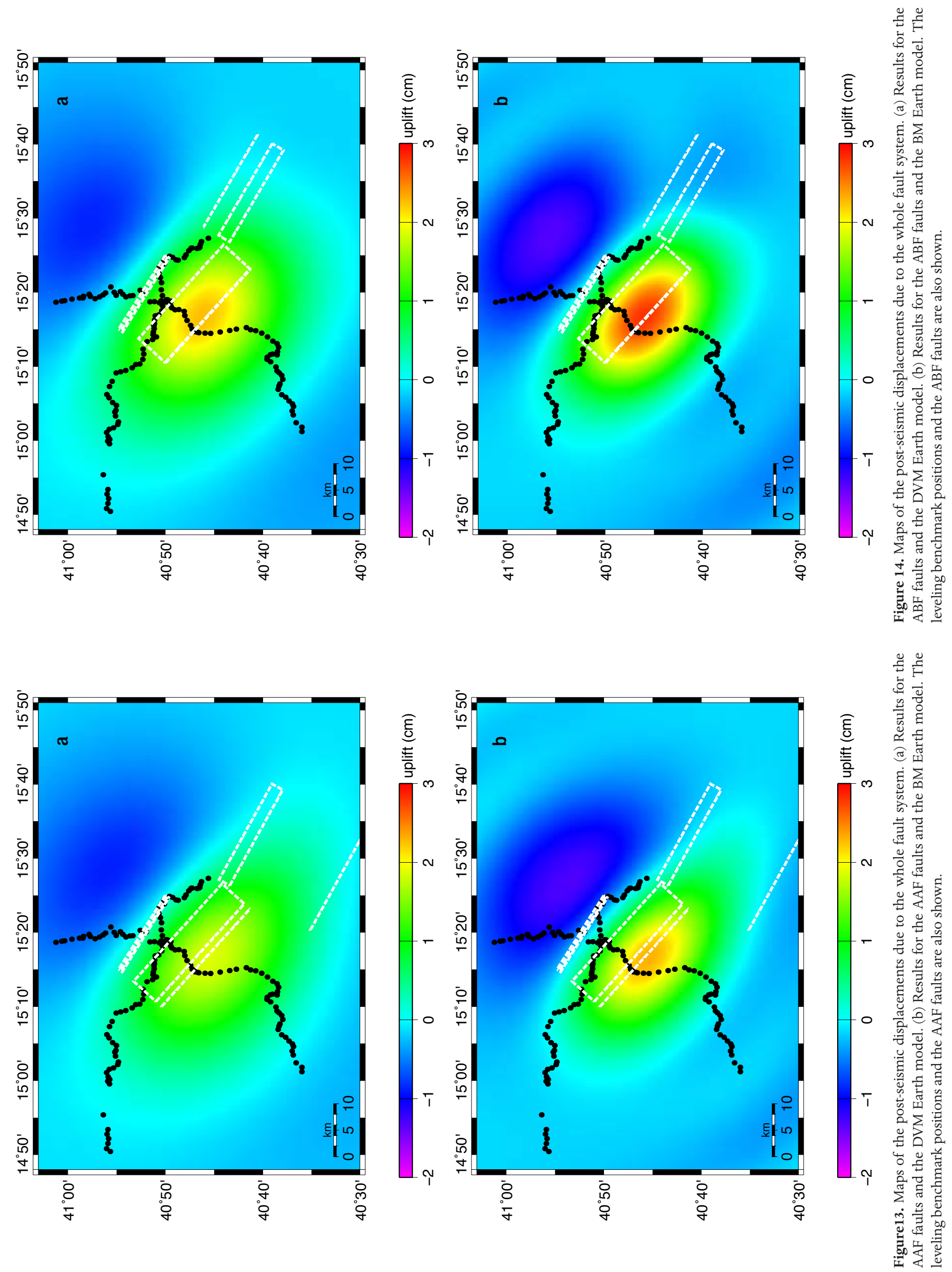
to FM, which is characterized by a shallower lower crust. The results also suggest that the most appropriate fault model that satisfies the post-seismic data is that referred to here as AAF (and analogously, ABF), thus confirming the findings from the inversion of the co-seismic leveling data [Amoruso et al. 2005a]. The equivalence between AAF and $\mathrm{ABF}$ is not surprising considering that the seismic moment was mainly released in the northern part of the epicentral area, and noting that the leveling lines do not intersect the region where the southern-most fault is located (the CZT3 leveling line crosses the main fault from the hanging wall to the footwall, the CZT2 leveling line goes through the northernmost part of the main fault, and the IGM81 leveling line intersects both the main fault and the F3 fault).

The experimental data (elevation differences between the 1981 and 1985 campaigns) have been obtained from leveling measurements, thus the zero level is actually arbitrary. In Figures 10, 11, and 12, we use the same zero level for all the plots related to the same Earth model. Of note, Dalla Via et al. [2005] recalled that in all likelihood the estimated contribution due to tectonic activities acts over wavelengths of hundreds of kilometers, thereby introducing a uniform bias over the whole area. However, its value is intrinsically linked to the arbitrary zero level of the experimental data. With respect to the comparable computations in Dalla Via et al. [2003] (see their Figure 2, red curve), the agreement between the measurements and the predictions seems improved. Even if our results are certainly consistent with measurements, we nevertheless found some discrepancies that might be related to the considered uniform slip distribution, and/or to the spatial resolution of our computations, and/or to the adopted Earth models, and/or to the effects of the topography [e.g. Armigliato and Tinti 2003]. For example, in the case of the CampaniaLucania earthquake, Armigliato and Tinti [2003] used a homogeneous two-dimensional domain with arbitrary topography of the free surface, and they observed that the computed misfits can be as high as $19 \%$ and $13 \%$ for the horizontal and vertical displacements, respectively, depending on the topographic profile. Further analyses are in progress on these aspects, although they are beyond the aims of the present study.

In conclusion, by our relocation of the main event and through the computation of fault-plane solutions of aftershocks and the velocity inversion, the results obtained in the present study provide the details of the largest recent earthquake that occurred along the Apennines. All of the data are in favor of a complex rupture mechanism, as already identified by many authors, which consisted of three separate events. The present study depicts a graben-like rupture, with the first event rupturing a ( $>20 \mathrm{~km}$ long) segment of a large, high-angle, NE-dipping, SE-NW-striking normal fault. The two successive ruptures occurred separately, first along the southern segment, and then along the northern segment of a complementary SW-dipping normal fault. This mechanism is well evidenced by the revised location of the hypocenter of the first event and the location of the aftershocks and their fault-plane solutions, as well as by the underlying 3D P-wave velocity structure. The model proposed by Amoruso et al. [2005a] that was based on the inversion of co-seismic vertical-displacement data, is confirmed by the present analyses, as it satisfies all of the available experimental observations. It thus better constrains the location and fault-plane solutions of the aftershocks, the velocity discontinuities, and the rupture observations at the surface. This conclusion is also supported by our analyses of the post-seismic data.

Acknowledgements. The Campania Region funded part of this study under Grant L.R. n. 5/2002 - Annuity 2005 - to Antonella Amoruso. We thank E. Del Pezzo, M. La Rocca, G. Milano and an anonymous reviewer for useful comments, and F. Tronca for help during the initial stages of this study. The Figures were generated using open-source software (GMT [Wessel and Smith 1998], and Grace).

\section{References}

Amato, A. and G. Selvaggi (1993). Aftershock location and P-velocity structure in the epicentral region of the 1980 Irpinia earthquake, Annali di Geofisica, 36 (1), 3-15.

Amoruso, A., L. Crescentini and R. Scarpa (2005a). Faulting geometry for the complex 1980 Campania-Lucania earthquake from levelling data, Geophys. J. Int., 162, 156-168.

Amoruso, A., L. Crescentini, E. D'Anastasio and P.M. De Martini (2005b). Clues of postseismic relaxation for the 1915 Fucino earthquake (central Italy) from modeling of leveling data, Geophys. Res. Lett., 32, L22307, doi: 10.1029/2005GL024139.

Armigliato, A. and S. Tinti (2003). Influence of topography on coseismic displacements induced by the Friuli 1976 and the Irpinia 1980 earthquakes (Italy), analyzed through a 2D hybrid model, J. Geophys. Res., 108, 2552; doi: $10.1029 / 2002 J B 002027$.

Bagh, S., L. Chiaraluce, P. De Gori, M. Moretti, A. Govoni, C. Chiarabba, P. Di Bartolomeo and M. Romanelli (2007). Background seismicity in the central Apennines of Italy: the Abruzzo region case study, Tectonophysics, 444, 8092; doi: 10.1016/j.tecto.2007.08.009.

Benz, H.M., B.A. Chouet, P.B. Dawson, J.C. Lahr, R.A. Page and J. Hole (1996). Three-dimensional P and S wave velocity structure of Redoubt volcano, Alaska, J. Geophys. Res., 101, 8111-8128.

Bernard, P. and A. Zollo (1989). The Irpinia (Italy) 1980 earthquake: Detailed analysis of a complex normal faulting, J. Geophys. Res., 94, 1631-1648.

Blumetti, A.M., E. Esposito, L. Ferreli, A.M. Michetti, S. Porfido, L. Serva and E. Vittori (2002). New data on the novembre 23, 1980, M 6.9, Irpinia-Lucania earthquake (Southern Apennine) coseismic surface effects, Studi Ge- 
ologici Camerti, Special issue, 2002, 19-27.

Cocco, M. and F. Pacor (1993). Space-time evolution of the rupture process from the inversion of strong-motion waveforms, Annali di Geofisica, 36 (1), 109-130.

Crosson, R.S. (1976). Crustal structure modelling of earthquake data 1: simultaneous least-squares estimation of hypocenter and velocity parameters, J. Geophys. Res, 81, 3036-3046.

Crosson, R.S., M. Martini, R. Scarpa, and S.C. Key (1986). The southern Italy earthquake of November 23, 1980: an unusual pattern of faulting. B. Seismol. Soc. Am., 76, 381-394.

Dalla Via, G., G. De Natale, C. Troise, F. Pingue, F. Obrizzo, R. Riva and R. Sabadini (2003). First evidence of post-seismic deformation in the central Mediterranean: crustal viscoelastic relaxation in the area of the 1980 Irpinia earthquake (Southern Italy), Geophys. J. Int., 154, F9-F14.

Dalla Via, G., R. Sabadini, G. De Natale and F. Pingue (2005). Lithospheric rheology in southern Italy inferred from postseismic viscoelastic relaxation following the 1980 Irpinia earthquake. J. Geophys. Res., 110, B06311; doi: 10.1029/2004JB003539.

Del Pezzo, E., G. Iannaccone, M. Martini and R. Scarpa (1983). The 23 november 1980 southern Italy earthquake, B. Seismol. Soc. Am., 73 (1), 187-200.

Deschamps, A. and G.C.P. King (1984). Aftershocks of the Campania-Lucania (Naples, Italy) earthquake of 23 November 1980, B. Seismol. Soc. Am., 74 (6), 2483-2517.

Giardini, D., A. Basili and E. Boschi (1996). Applying the relative hypocentre location approach: where was the 1980 November 23 Irpinia earthquake?, Geophys. J. Int., 127, 605-615.

Kissling, E., W.L. Ellsworth, D. Eberhart-Phillips and U. Kradolfer (1994). Initial reference models in local earthquake tomography, J. Geophys. Res., 99, 19635-19646.

Lee, W.H.K. and C.M. Valdes (1985). HYPO71PC: A personal computer version of the HYPO71 earthquake location program. U.S. Geological Survey Open-file Report 85-749, $43 \mathrm{pp}$.

Pantosti, D. and G. Valensise (1990). Faulting mechanism and complexity of the November 23, 1980 Campania-Lucania earthquake, inferred from surface observations, J. Geophys. Res., 95, B10, 15319-15341.

Pavlis, G.L. and J.R. Booker (1980). The mixed discrete-continuous inverse problem: Application to the simultaneous determination of the earthquake hypocenters and velocity structure, J. Geophys. Res., 85, 4801-4810.

Pingue, F., G. De Natale, V. Bonasia, V. Cagnetti, E. Del Pezzo, M. Martini, R. Scarpa and A. Zollo (1988). Il terremoto irpino-lucano del 23 Novembre 1980, Mem. Soc. Geol. It., 41, 1163-1169.

Pingue, F., G. De Natale and P. Briole (1993). Modeling of the 1980 Irpinia earthquake source: constraints from geodetic data, Annali di Geofisica, 36 (1), 27-39.

Pollitz, F.F. (1992). Postseismic relaxation theory on the spherical Earth, B. Seismol. Soc. Am., 82, 422-453.

Reasenberg, P. and D. Oppenheimer (1985). FPFIT, FPPLOT and FPPAGE: Fortran computer programs for calculating and displaying earthquake fault-plane solutions, U.S. Geological Survey Open-file Report 85-739, 109 pp.

Spencer, C. and D. Gubbins (1980). Travel-time inversion for simultaneous earthquake location and velocity structure determination in laterally varying media, Geophys. J. Roy. Astr. S., 63, 95-116.

Valensise, G., A. Amato, L. Beranzoli, E. Boschi, M. Cocco, D. Giardini and D. Pantosti (1989). Un modello di sintesi del terremoto campano-lucano del 23 Novembre 1980, In: Atti dell’VIII Convegno Annuale del Gruppo Nazionale di Geofisica della Terra Solida (Rome, Italy, November 7-9, 1989), Esagrafica, Roma, 151-172.

Wessel, P. and W.H.F. Smith (1998). New, improved version of generic mapping tools released, Eos Trans. AGU, 79 (47), 579; doi: 10.1029/98EO00426.

Westaway, R. and J. Jackson (1987). The earthquake of 1980 November 23 in Campania-Basilicata (Southern Italy), Geophys. J. Roy. Astr. S., 90, 375-443.

Westaway, R. (1992). Revised hypocentre and fault rupture geometry for the 1980 November 23 Campania-Basilicata earthquake in southern Italy, Geophys. J. Int., 109, 376-390.

${ }^{\star}$ Corresponding author: Roberto Scarpa,

Università degli Studi di Salerno, Dipartimento di Matematica e Informatica, Fisciano (Salerno), Italy; email: roberto.scarpa@sa.infn.it.

(C) 2011 by the Istituto Nazionale di Geofisica e Vulcanologia. All rights reserved. 